\title{
GENDER-RELATED DIFFERENCES IN THE IMPACT OF TROPICAL DISEASES ON WOMEN: WHAT DO WE KNOW?
}

\author{
CAROL VLASSOFF* AND ELSSY BONILLA†
}

* Special Programme for Research and Training in Tropical Diseases, World Health Organization, Geneva, Switzerland, and †Centro de Estudios sobre Desarrollo Economico, Universidad de Los Andes, Bogota, Colombia

\begin{abstract}
Summary. This paper explores the importance of gender differences in the impact of tropical diseases on women. Malaria and schistosomiasis are used as examples but most of the observations also apply to other diseases endemic to developing countries. The distinction between sex and gender is discussed and evidence of sex and gender differences in the determinants and consequences of malaria and schistosomiasis, particularly their economic, social and personal dimensions, is reviewed. Issues on which research and intervention studies are needed are identified.
\end{abstract}

\section{Introduction}

If sustainable development is the latest challenge to the international community, then women, more than ever before, should be at the front and centre of all action strategies. This is not a matter of social justice, nor a feminist issue; it is simple common sense (Huston, 1990).

Women's health as an end in itself has rarely been at the forefront of international development programmes or national health planning. Attention to women's health in developing countries has been motivated largely by other concerns. Women have tended to be seen as the vehicle through which specific goals such as family planning and child survival could be achieved rather than as the primary beneficiaries of development programmes.

This paper, however, is based on the premise that understanding the health of women in developing countries, and the special health risks they face, is important in itself, firstly, because surprisingly little is known about non-reproductive aspects of women's health in non-industrialized countries, and secondly, because effective interventions to improve women's health depend upon adequate knowledge of these issues. Through the benefits of improved knowledge and appropriate interventions, women's active participation in disease prevention and health procurement for their families and the larger society can thus be facilitated. 
The lacunae in knowledge of gender differences in health in developing countries could be demonstrated with reference to a large number of important infectious diseases, as well as several non-communicable diseases. The 'tropical diseases' include six major diseases-malaria, schistosomiasis, leprosy, filariasis (onchocerciasis and elephantiasis), trypanosomiasis (African sleeping sickness and Chagas disease) and leishmaniasis which are considered by the World Health Organization to be among the most pervasive and neglected diseases in the world. The Special Programme for Research and Training in Tropical Diseases (TDR) was created in 1974 to address the urgent need for greater understanding of these diseases, especially in relation to improved disease control measures. In this paper, only malaria and schistosomiasis are discussed as examples of the broader group of diseases.

Tropical diseases are 'diseases of poverty' because it is the poor and underprivileged who are most at risk and who, because of precarious living conditions and often inadequate health services, experience the greatest morbidity. Malaria is found in approximately 100 countries; approximately 270 million people are infected and 110 million clinical cases are reported each year. It is the most widespread of the tropical diseases and causes one to two million deaths per year (WHO, 1991). Schistosomiasis (including the urinary, $S$. haematobium, and intestinal, $S$. mansoni and $S$. japonicum, forms) is found in 76 countries; approximately 200 million people are infected, and approximately 200,000 die each year from morbidity associated with the disease (WHO, 1991). Definitive distributions of malaria and schistosomiasis by sex are not available: studies report divergent findings, depending on local conditions of exposure, cultural habits and life cycle period (Brabin \& Brabin, 1992). Overall it seems that men and women are infected in equal numbers by these diseases but women, being generally the poorest and most disadvantaged members of families in developing countries, are likely to be affected more intensely by these diseases than men.

Research on the social and economic factors leading to sex differences in exposure to disease, intensity of infection, duration of incapacity, care given during illness, access to and utilisation of services, impact of illness on production and domestic work, social activities and personal life, has been extremely limited. The social and economic aspects of tropical diseases have received relatively little study and what research exists has tended to be driven by biomedical priorities.

This paper (1) reviews existing evidence of sex and gender differences in the determinants and consequences of tropical diseases, using malaria and schistosomiasis as examples, (2) identifies issues on which more research is needed, and (3) highlights areas where, on the basis of existing knowledge, appropriate interventions can be proposed. The concept of gender, as opposed to sex, is considered an appropriate framework for the present analysis, and is briefly discussed. A more detailed discussion of the 'gender framework' for tropical diseases is available elsewhere (Rathgeber \& Vlassoff, 1993).

\section{Gender framework}

It is appropriate to apply the concept of gender to tropical diseases particularly because of the paucity of information on their determinants and consequences with 
respect to females. Most of the biomedical literature, except that relating to the period of reproduction, is based on the study of males. This applies to hospital-based studies of morbidity, clinical trials of drugs and other interventions including, often, community-based field studies.

With respect to women, the period of pregnancy, childbirth and reproduction has received most attention in the medical research (Paolisso \& Leslie, 1993; Parker, 1992; Graham \& Campbell, 1990). Because women, as childbearers, are perceived as more frequently responsible for family planning decisions and because female methods of contraception are more plentiful and apparently more acceptable in developing countries, women have been the focus of fertility research and birth control programmes. Clearly, sex differences during the reproductive period cannot be ignored, but the presumption has been that men and women are otherwise similar. A limited amount of epidemiological research has been concerned with differences between males and females in disease prevalence and risk factors, but it has rarely touched upon broader determining factors, such as social, economic and cultural conditions.

Research on women's health in industrialised countries, however, has taken a wider gender perspective (Payne, 1991; Verbrugge, 1985; Hibbard \& Pope, 1983). This incorporates not only contextual problems of women's roles and expectations but also relationships between individuals and society, such as structural barriers that lead to status differentials. In many societies, for example, social barriers are created on the basis of sex, females being relegated to the private or domestic sphere and men to the public domain (Elshtain, 1981).

The main elements of a gender framework for health research are first, that women are seen not merely as productive or reproductive agents but rather as persons in a more holistic way with needs and qualities that go beyond purely biological considerations. Second, it requires that women's health be understood within a broad sociocultural and economic context, taking into account their economic or productive activities, both within the home and outside, social roles and interactions with others, as well as personal attitudes, perceptions and needs. Third, it recognises that while both males and females in rural areas of countries where tropical diseases are endemic suffer from class inequality, poverty and deprivation, women are particularly disadvantaged due to structural factors within society that frequently make them completely dependent on men economically and allot them a considerably lower social status (Rathgeber \&. Vlassoff, 1993).

Status differences may act as constraints upon women's decision-making powers regarding their own health care and that of their children. A gender approach also takes into account the relatively heavy burdens placed upon women by virtue of traditional expectations, including domestic work, child-rearing, health provision to family members, responsibility for many community development activities and, frequently, outside employment. The gender perspective also recognises that power and status differentials between health provider and patient may affect diagnosis and treatment, and that females may be at particular risk of misdiagnosis and inferior treatment at health facilities by virtue of their status in society (Foucault, 1978). It considers that women's understanding of their own feelings and bodily symptoms are often undervalued in medical diagnoses and that women's perspectives may be lacking in the development of disease control strategies. 


\section{Sex differences in morbidity and mortality from tropical diseases}

Biomedical research on sex differences in diseases such as malaria and schistosomiasis has focused mainly on pregnancy and the reproductive period. The possibility of placental transmission of some infectious diseases and of maternal-induced protection against infection has also received considerable attention. A few important sex differences in malaria and schistosomiasis are noted because of their relevance to the discussion of gender issues.

Most of the research on malaria in females has concentrated on pregnancy and pregnancy outcomes, and on the interaction of malaria with anaemia and other infections and with early childbearing. Apart from the pregnancy period, there is little evidence of important gender differences in malaria infection and such variations appear to be attributable to differential exposure (Reuben, 1992). Females, however, have higher antibody responses to the disease, except during pregnancy when immunity status is altered. Malaria is one of the most important causes of maternal mortality among young pregnant women in endemic areas, especially when associated with anaemia and low levels of immunity. Among those with no immunity, malaria during pregnancy may cause abortions, stillbirths and low birthweight babies. Where malaria transmission is stable, congenital malaria with clinical manifestations is rare, and there is evidence that placental transfer of maternal antibodies takes place (McGregor \& Wilson, 1988). Severe implications of malaria for pregnant women and young children are a serious problem in endemic areas, and research on ways of ensuring safe, effective and timely treatment for these high-risk groups is of utmost importance (see Brabin, 1991).

Schistosomiasis also has important implications for females, yet these have received scant attention. Recently some disturbing hypotheses concerning both known and possible effects of schistosomiasis on women have been advanced (Feldmeier \& Krantz, 1992; Feldmeier, Krantz \& Poggensee, 1993). In endemic areas schistosomiasis frequently leads to complications in pregnancy including ectopic pregnancy, premature birth and abortion, as well as placental involvement causing damage to the fetus and newborn. During gestation, delivery and breast-feeding, the mother's antischistosome antibodies may be transmitted to neonates but the frequency and distribution and the impact on the unborn child have not been systematically studied (Feldmeier \& Krantz, 1992). Another consequence of schistosomiasis, particularly $S$. haematobium, is genital tract involvement, a generalised pelvic disease involving bladder, ureters, rectum and external and internal reproductive organs. Research on the prevalence and long-term sequelae of female genital syndromes is, however, deficient, as are studies of interactions between schistosomiasis and other conditions such as anaemia, sterility and cancer (Feldmeier \& Krantz, 1992).

\section{Gender as a determinant of tropical diseases}

Gender, as well as sex, differences affect people's risks and responses to tropical diseases, and the determinants and consequences include economic, social and personal dimensions. 


\section{Economic determinants}

Only a few studies have investigated the economic determinants of malaria and schistosomiasis, and even fewer have examined differences by sex or gender. Existing evidence relates mainly to exposure as a result of occupational activities, as well as the probable (though largely undocumented) impact of broad economic policies on gender differences in risk of infection.

Economic activities and exposure. Economic factors include market oriented activities and the domestic tasks used to produce goods and services for households for general family well-being. Productive tasks involve different levels of risk for tropical diseases, depending on the degree of exposure to vectors such as mosquitoes or snails. For example, Bonilla et al. (1991) found that women in poor housing and those fetching water outside the household had more malaria than those cooking in adequate kitchens or those with water in their houses. Women's more frequent contact with water tends to expose them to greater risk of schistosomiasis, although adolescent boys often have a higher prevalence and intensity of the disease than girls of the same age because of their habit of playing in rivers and canals infested with snails, the disease vectors (Chandiwana \& Christensen, 1988).

It is important to be aware not only of the various tasks women and men perform, but also of their changing nature over time, when considering exposure to infection. For example, the extent of female infection could be underestimated because the full range of women's activities are not taken into account in estimates of prevalence, i.e. when the private-public dichotomy is interpreted too literally. Michelson (1992) points out that in some areas where the incidence of certain diseases is currently considered to be higher among men, modernisation may be leading to higher risks of disease and infection among females as they increasingly assume traditional male roles.

Structural adjustment policies. In recent years in both rural and urban areas of many countries where tropical diseases are endemic, structural adjustment policies have raised women's workloads. Their need for cash has increased as a result of changes in traditional social systems and greater dependence on commodities. Hence they have had to earn cash themselves or rely on other household members, while the number of household members at home to assist with domestic tasks is also reduced. At the same time, pressure on land has meant that less space is available for growing food, the best land usually being dedicated to cash crops (Boserup, 1989). In Latin America, for example, during the economic crisis of the $1980 \mathrm{~s}$, nutritional levels of the population were badly affected in Peru and Ecuador (Bonilla, 1992). Although nutrition among both males and females was adversely affected, women played a more critical role in preventing further deterioration of family nutritional levels by organising community kitchens.

Few studies have investigated the impact of structural adjustment on the demand for particular types of services and there appear to be no studies on its effect on malaria or schistosomiasis treatment or prevention. However, Yoder (1989) found substantial drops in visits to clinics for childhood immunisations and preventive care in Swaziland, and Loewenson, Sanders \& Davies (1991) found that use of maternal and antenatal services was highly sensitive to changes in costs of health care in Zimbabwe; Parker (1986) noted that utilisation of primary health care facilities in the Punjab, 
India, increased dramatically as a result of the provision of free care for women and children, including antenatal care. As pregnant women are a particularly high risk group for malaria and need to be encouraged to make greater use of antenatal services, the fact that increases in costs could act as a deterrent to their utilisation is cause for concern.

The impact of economic problems and policies on women varies considerably by geographical setting, but women tend to be the worst off in situations of scarcity (UNICEF, 1987). Evidence from all developing regions indicates that women have longer working hours than men (Raikes, 1989; Adagala 1991; Florez \& Bonilla, 1991; Feijoo \& Jelin, 1987; Babb, 1987; Khan, Tamang \& Patel, 1990), especially when their double load of domestic and remunerated work is considered. Furthermore, the increase in households headed by women in developing countries (UN, 1991) is a matter of concern: these households are not only lowest on the social ladder but they also tend to have the poorest land and less access to credit than other households (Raikes, 1989).

Measurement of the impact of economic and social policies on women is hampered by inadequate statistics on women's contributions to the economy as well as on disease prevalence and incidence by sex. For example, labour force statistics frequently undercount female labour in the informal sector and indicate a much lower proportion of women working than of men. Statistics on disease and health care coverage also tend to be given by total numbers only.

\section{Social determinants}

Social factors that may affect gender differences in the determinants of tropical diseases include: cultural norms and practices prescribing different roles for males and females and thus affecting exposure to risk of infection; gender status within the household affecting knowledge and access to information and preventive measures; and status differences within the community or local power structures affecting women's freedom to participate in health promotion activities.

Cultural factors and exposure. Differences in cultural practices such as the seclusion of females in some countries frequently entail different risks of exposure. Women in Muslim countries, for example, generally have less exposure to water and lower rates of schistosomiasis than men (Michelson, 1992). A study of malaria in India found that men who sat outside on the porch in the early evening were bitten by mosquitoes more frequently than women who spent more time in the kitchen, protected from bites by the smoke of cooking fires. On the other hand, women were more at risk of respiratory infections (Reuben \& Panicker, 1979). The more extensive clothing often worn by women also tends to protect them more than men from insect bites (Reuben \& Panicker, 1979; Silva, 1988).

Status within the household. Women's status within the household may affect their access to information about disease and preventive measures as well as their ability to take such measures or to seek treatment for themselves and their families. There is growing evidence that the mother's freedom to make decisions has considerable influence on the health of her children (Dyson \& Moore, 1983). Doan \& Bisharat (1990) reported that, in Jordan, women's autonomy in the household had a strong influence on the nutritional status of their children. In households where the mother-inlaw was present and the young wife had little decision-making power, children's weight 
for age was significantly lower than in families where the mother was head or co-head of the household. Effective communication between husbands and wives also seems to have an important influence on family planning decision-making (Joesoef, Baughman \& Utumo, 1988; Adamchak \& Adebayo, 1987; Clifford, Lake \& Brannon, 1987).

A recent study in Mali found that household status was an important determinant of patterns of seeking treatment for malaria. The household heads, most of whom were male, had ultimate decision-making power with respect to treatment and payment for treatment. Women, however, played a more important role in health decisions and treatment than men who were not heads of households. Men were more concerned about male children's illnesses, and women were given more automony in deciding about their own health and that of female children (Traore, Coulibaly \& Sidibe, 1993).

Feldmeier et al. (1993) note that status within the household may affect women's ability to travel to health centres for treatment of schistosomiasis, and that a woman may have to be accompanied by a male, greatly restricting her freedom to travel for non-life-threatening illnesses. Women's seclusion may also affect their participation in morbidity surveys as the authorisation of the husband may not be given, leading to under-reporting of women.

In a traditional community in Ecuador, Finerman (1989) reported that women derived considerable prestige from their role as principal health care provider in the family. The household context of health was greatly valued by all, despite wide recognition of the effectiveness of modern medicines and the availability of inexpensive traditional healers. Women considered that seeking care outside the home put them in a dependent position whereby they lost personal control over the care of the patient. Their role as primary care giver was therefore seriously threatened by moving outside the household for health services.

The sex of family members is known to influence access to food and nutrition in many cultures (Chatterjee, 1991; Popkin \& Doan, 1990). In India, for example, Khan et al. (1990) found that while all members of the family ate the same food, male adults and children received the largest amounts of nutritious food such as dairy products because they were considered the 'breadwinners'. In Bangladesh, Kabeer (1991) reported that wives not only suffered from food deprivation in times of scarcity but were frequently beaten by their husbands who, by blaming their wives for mismanaging household affairs, attempted to deflect attention from their own inability to provide for their families. The degree to which inequality of food distribution affects tropical disease infection has not been investigated but it is known that adolescent females who are poorly nourished and anaemic have a greater risk of morbidity from malaria and other parasitic infections than those with adequate nutrition (Brabin, 1991; Harrison et al., 1985).

Status within the community. Status within the community may also influence women's participation in community health promotion strategies. A study of a trachoma programme in Tanzania indicated that women were unwilling to participate without the support of husbands and other community members (McCauley et al., 1990). Many development projects aimed at women have had little impact because of their failure to recognise the context in which the interventions or the application of newly acquired skills will ultimately take place. Boserup (1989) notes that projects designed to give women technological training in agriculture have failed or been 
'sabotaged by local communities', and concludes that this is either because male decision-makers are convinced women are unable to learn or because they want to preserve the status gap between the sexes.

Because of their lower position within the community women often have little say in the selection of village health volunteers and hence may feel little empathy with local health personnel (Ferguson, 1986; Reuben, 1992). As women are key to the successful implementation of community interventions for disease control, their involvement could probably be increased by including them in the planning process and in the selection of key personnel.

Community disapproval of extra-marital pregnancies also led to low utilisation of hospitals by pregnant girls for malaria treatment in Nigeria (Okonofua et al., 1992) because parents hid their pregnant daughters at home to avoid shame. In Ghana, too, unmarried pregnant girls made very little use of health services when ill with malaria, but this seemed to have been related more to the costs of travel and treatment than to shame of community exposure of their condition (Agyepong, 1992).

\section{Personal determinants}

A gender-related area, the personal sphere, includes women's feelings and relationship to their psychological and physical beings. This section explores women's knowledge about malaria and schistosomiasis and how this is affected by their relationships with health providers, and women's non-reproductive concerns.

Knowledge about tropical diseases. The positive relationship between mother's education and child survival is well documented. Cleland \& van Ginneken (1988), in a comprehensive review of the literature, noted that, on averge, each increment of a single year in mother's education corresponded to a 7-9\% decline in infant mortality. Health beliefs and domestic practices were thought to be of considerable importance in explaining this association. Mbacke \& van de Walle (1987) found that the use of mosquito nets and coils was significantly related to maternal education and that in West Africa the latter was a strong predictor of mortality.

While it is known that education is linked to practical knowledge, the degree to which knowledge about disease prevention and control is associated with behaviour is less clear. Health education frequently does not lead to changes in behaviour, as is evidenced by continued smoking among educated and informed people in developed countries. Moreover, sometimes there is a missing link in knowledge about a disease that makes preventive or coping actions ineffective. For example, a study of women suffering from malaria in Saradidi, Kenya, indicated that $90 \%$ knew that they had malaria but only $29 \%$ were taking chloroquine. Some had even experienced miscarriages that they recognised to be associated with malaria. The most common reason given for not taking prophylaxis was lack of knowledge of its availability $(53 \%)$, followed by fears of side effects. Only $2 \%$ said that they considered it harmful for pregnancy (Kaseje, Sempebwa \& Spencer, 1987), which is surprising as it is well known that fears of abortion from chloroquine are widespread in Africa. However, if the reported reasons are largely true, women lacked only one piece of vital information, that the drugs were available locally.

To some extent, provider-patient relationships are responsible for women's inadequate health knowledge. Women have central nurturing and health care roles in the 
family and a large amount of traditional knowledge at their disposal. Several studies in industrialised countries have shown that women, throughout their lives, experience more physical and psychological illness than men, even though they live longer (Mechanic, 1976; Hibbard \& Pope, 1983; Malterud, 1987; Kandrack, Grant \& Segall, 1991). Bird (1991) attributed this to women's longer working days and fewer hours of leisure and sleep. Yet women's experience of symptoms is frequently given little credence by health professionals, with the result that women are placed in a dependent position whereby they may lose confidence in their own perceptions and knowledge base. At the same time the modern health sector loses an important female resource for more effective and locally appropriate primary health care strategies. There is little evidence that women suffer more symptoms of illness from tropical diseases, but because of their 'invisibility' and the fact that they tend to report for treatment less readily than men, female morbidity from these diseases may well be underestimated.

Lack of salience of non-reproductive health concerns. Attention to women's health in developing countries has focused more on reproductive issues than on other aspects. Although reproduction and motherhood no doubt assume a high place among women's personal priorities it is unlikely that they think of their health primarily in reproductive terms. The lack of correspondence between women's views of their own health and those of the health services may mean that women hesitate to report physical problems unless they are specifically related to reproductive concerns, creating psychological conflicts for women when they are ill. The overriding attention to birth control in reproductive health issues may also discourage women from visiting formal health services because of fears of sterilisation in countries with vigorous family planning policies. The alienation of women from health services may thus be a determinant of tropical diseases because it may impede women's access to preventive drugs for themselves and their families, hence putting them at greater risk of disease.

\section{Gender differences in consequences of tropical diseases}

\section{Economic consequences}

Tropical diseases have important economic consequences for women, including effects on women when others are ill, effects on women when they themselves are ill, effects on others when women are ill and costs to women of treatment.

Effects on women when others are ill. Bonilla et al. (1991) observed that when other members of the household were ill women's work days lengthened, their work load became heavier and some of their activities were deferred. Women used their leisure time to care for sick family members or to replace the labour of the incapacitated person. They also maintained their other daily duties to the extent possible. Women experienced considerable anxiety because of their increased work load and worry over sick family members. Moreover, they discounted these economic and psychological costs to themselves and reported feeling guilty when they were unable to complete all the tasks expected of them in a normal day. This conflict between expected roles and physical limitations added to women's stress and feelings of personal inadequacy.

The reduction of state-supported health services in many developing countries in recent years has meant less access to clinics, longer waits for services and poorer care. This may mean that women are less inclined to use biomedical health services and that 
their burden for the provision of care to family members has increased (Leslie, Lycette \& Buvinic, 1986).

Effects on women when they themselves are ill. The economic effects of illness upon women have received little study. Research on the economic impact of diseases such as malaria and schistosomiasis has focused mainly on the individual worker in the labour force and the effects on the household as a whole have tended to be underestimated (Prescott, 1989). There is some evidence that when women are ill they wait longer to report their illness than men, partly because of guilt and also because they tend, more than men, to treat themselves and to consult traditional services (Ettling et al., 1989; Cosminsky, 1987; Beljaev et al., 1986). Bonilla et al. (1991) reported that women in malaria endemic areas of Colombia went for treatment only after they were very ill, disregarding their own sickness until it severely interfered with their daily activities. Bonilla argued that women's tasks could not be easily deferred because they were essential for the normal functioning of the family. Because they postponed treatment women took longer to recover than men and often returned to their normal domestic duties while they were still debilitated. Similar findings have been reported in India (Murthy, 1982).

Parker (1992) substantiated the observation that women tend to overcompensate for their illnesses. The amount of cotton picked in a day by women infected with $S$. mansoni was compared with that picked by uninfected women, and the domestic tasks of another group of infected women were compared with those of uninfected women. Overall, there was no significant difference in the total amount of cotton picked by the two groups but infected women worked for a shorter time. Some women did not return to the fields in the afternoon because they were too tired, indicating that they attempted to pick as much cotton as possible in the mornings in order to compensate for the weakness they experienced later in the day. Also, infected women spent significantly less time on ancillary agricultural activities such as collecting weeds for goats. On the other hand, time spent on domestic work, child care or leisure activities did not vary by infection status, perhaps because domestic work was less intensive and did not involve exposure to sunlight. However, as this study was based on small groups of women, definitive conclusions about the impact of infection on productivity cannot be drawn.

Effects on others when women are ill. The care of women during illness has been found to be less comprehensive than that of men. Bonilla et al. (1991) found that when a woman was ill with malaria another woman, usually a relative or neighbour, helped with essential tasks, but that her duties were never fully carried out, and when the woman recovered she had to catch up with things left undone during her illness. In Nigeria, Watts, Brieger \& Yacoob (1989) similarly reported that female networks tended to supply most of the support to women ill with Guinea worm disease; men also helped but to a lesser extent. The activity about which women were most concerned was child care; the most neglected activity was self-care, including washing themselves and their clothes and eating adequate meals. Some women ate and drank sparingly in order to avoid the discomfort of having to go outside to defecate. Also, women who had small businesses to augment their family's income could not ask anyone else to take over these activities, and they were also often forced to spend their small savings on medicines and other needs during their illness. 
Costs of treatment. The extent to which costs of treatment and seeking care affect women's health-seeking behaviour remains unanswered. Leslie \& Rao Gupta (1989) suggest that women with little or no cash resources may be attracted to traditional healers who are more likely to accept payment in kind. Studies from South Asia suggest that in circumstances of poverty, boys are more likely to receive medical attention than girls (Das Gupta, 1990; Hossain \& Glass, 1988; Wyon \& Gordon, 1971). A study in an Andean community of factors affecting health-care decisions found that, while costs were among the constraints facing traditional village women when seeking care for ill family members, cultural values favouring home care and women's autonomy within the household were more important reasons for rejecting modern services (Finerman, 1989).

\section{Social consequences}

The social consequences of tropical diseases are considered within the context of women's distinctive behaviour when ill, in terms of health-seeking behaviour, including case reporting and type of treatment sought, and of the treatment of infected women by society.

Health-seeking behaviour. Among the social consequences of tropical diseases by gender, health-seeking behaviour has received most attention. Ettling et al. (1989) noted important sex differences in attendance at malaria clinics-a ratio of $6: 1$ in favour of males-yet population-based surveys in the same area revealed no significant gender differences in infection. Attributing the difference in reporting to gender gaps in access, time, knowledge and cost factors, a mobile malaria clinic was introduced to the area but male-female differences in attendance still prevailed although at a lower ratio of $4: 1$. Other constraints to treatment at formal health services persisted, rooted in gender barriers such as status, privilege and exclusion. Ettling et al. identified other obstacles as well, including deep-seated female preferences for purchasing drugs in pharmacies and shops, emotional benefits from interaction with traditional healers, satisfaction obtained from injections and dislike of 'strong' drugs and finger pricks administered in the clinic.

A study of age and sex composition of passive cases of malaria detected at 39 primary health care centres in Orissa, India (Beljaev et al., 1986), reported similar findings to those of Ettling et al. in Thailand. Reuben (1992), discussing the similarities between the two studies, concluded that underprivileged women who are burdened with household responsibilities and child care are often not counted in official malaria statistics, and that they go 'unnoticed because of the masking effect of the well-known greater occupational risk of malaria for adult males' (Reuben, 1992). Apart from the significance of these findings for gender analysis, the underreporting of women in malaria clinics negatively affects the accuracy and completeness of official epidemiological statistics.

There is considerable evidence that women in developing countries seek out a wide variety of health care, ranging from self-treatment to voluntary and government centres (Cosminsky, 1987; Raikes, 1989; Reuben, 1992). Women have to weigh the potential advantages of treatment-seeking against known negative factors such as walking long distances, missing work or foregoing domestic tasks, and possible disappointment if the medical practitioner is absent or if drugs or other supplies are not 
available. Whereas women may hesitate to visit a clinic for their own health concerns they sometimes use the opportunity of bringing their children to health care facilities to have themselves examined as well. Beljaev et al. (1986) noted, for example, a strong correlation betweem the reporting of mothers aged 25-39 and young children.

Societal reaction. The stigma associated with some tropical diseases is another reason inhibiting early case reporting. Although little research exists on differences in stigma by sex, it seems probable that women will be at greater risk of societal alienation than men. While this is perhaps to be expected with respect to obviously disfiguring diseases such as leprosy or lymphatic filariasis, it is less apparent for relatively common diseases such as schistosomiasis. Nonetheless, there is growing evidence that schistosomiasis is associated with immoral sexual behaviour among women in several African countries while for men it is considered a sign of virility. As fear of physical disfigurement and consequent rejection by family and friends is a known deterrent to early case reporting, women are likely to be particularly hesitant to reveal their symptoms to kin or health personnel.

\section{Personal consequences}

The literature on personal consequences of malaria and schistosomiasis is scarce, but there is evidence that women suffer more intensely from stress and from feelings of frustration with treatment received at health services.

Stress. Women are subject to a high degree of stress accompanying ill-health, both their own or that of family members (Ferguson, 1986; Raikes, 1989; Bonilla et al., 1991). In areas where infant mortality is high mothers continually experience some uncertainty about the survival of their infants. In addition, they are mainly responsible for the care of the elderly, and for the care of return migrants when they are ill or of visitors to their rural homes.

Sub-fecundity was found to result from stress associated with malaria infection, heavy work loads and physical exhaustion during peak agricultural periods in two rural districts of Tanzania. Bantje (1988), in a study of biological and social factors associated with seasonal variations in births found that the seasonality of births did not correspond to the pattern expected on the basis of climatic factors, but to stress related to gender roles and expectations. Bantje also highlighted a further stress-causing circumstance associated with food shortages (although it was not mentioned as a contributing factor in his study), that women are often obliged to give sexual favours in return for food or cash. This meant that women were forced by hunger to agree to sexual relations even in late stages of pregnancy, greatly increasing chances of pregnancy loss.

In addition to the stress accompanying poverty and heavy economic responsibilities many women in countries where tropical diseases are endemic are illiterate and inadequately informed about mechanisms of disease transmission and prevention of infection. It would seem likely that, confronted with disease symptoms such as malarial fevers or blood in urine, women will experience fear and confusion. In their efforts to cope with their anxiety they are likely to seek relief from familiar, traditional sources that frequently provide caring, if often ineffective, treatment.

Negative reactions to formal health services. Women consult a variety of sources for treatment of disease, and several studies have indicated that the reason women prefer 
traditional healers is that they are provided with explanations for their illness which make sense to them. In Guatemala, for example, Cosminsky (1987) reported that women preferred spiritual healers because they provided explanations for illness that corresponded to women's socio-cultural reality. Traditional practitioners attributed an illness to someone's evil wish, while medical personnel simply instructed patients on treatment procedures. Female patients received unsatisfactory and incomplete explanations, and were sometimes blamed for bringing their children too late for treatment. Health workers seemed unaware that such women often had come in a state of virtual desperation, after making an extremely arduous trip to town. In the Philippines, Lariosa, Abaya \& Ventura (1987) found that patients' negative perceptions of health workers negatively affected their use of biomedical health services.

Cosminsky (1987) drew attention to another problem traditional women felt in Guatemala, namely that health personnel did not respect deep-seated cultural norms of privacy. Even for serious problems such as 'fallen uterus' which interfered with their activities, women preferred to consult midwives because they were examined clothed, a factor of special sensitivity with respect to the lower part of the body. Values such as these may well influence female patients' willingness to visit health services for treatment of lesions or genital problems related to tropical diseases.

\section{Conclusion}

This review of gender differences in the determinants and consequences of tropical diseases, using malaria and schistosomiasis as illustrations, has shown that knowledge in this area remains incomplete. On the biomedical side, even the best researched areas-pregnancy and reproduction-leave many questions unanswered. While some exposure studies by sex have been conducted, careful studies are few for most of the diseases, and longitudinal studies of risk factors by sex are extremely rare. Although statistics on these dimensions are usually gathered in epidemiological investigations, they are frequently not analysed or reported. Sex differences in clinical manifestations of many tropical diseases and associated morbidity also remain largely unexplored, as was demonstrated with respect to schistosomiasis. Gender differences in the effects of chemotherapy for treatment of these diseases may also be important.

Marked differences exist in health-seeking behaviour between developed and developing countries, and the reasons for these differences deserve further exploration. Factors affecting women's use of community health services in countries where diseases are endemic - sex of health personnel, perceived quality of treatment, cultural conflicts between biomedical services and women's traditional role as health providers for their families, fear of detection of stigmatising diseases and costs of services-should be investigated in more depth. -

Given the scarcity of professional knowledge about these issues, it is not surprising that women, especially in poor rural areas of developing countries, are largely unaware not only of the risks these diseases pose for their health but also of many of the signs and symptoms of the diseases. Their understanding of the possible implications of their own infection status for their offspring is likely to be even more inadequate. There are several areas, however, in which sufficient information is available to begin to test practical interventions. The possibility of greater empowerment of women through 
mutual dialogue and understanding - not only by means of the provision of accurate information on the part of medical personnel, but also through better communication between provider and patient concerning the perception of illness-is a promising area for intervention-oriented research. Other ways of improving the accessibility of health services to women, such as adapting working hours to their needs or involving women in the planning of community health facilities, should also be explored. Also, as mothers are known to have themselves examined when bringing children for treatment, the cost-effectiveness of integrating tropical disease education with maternal-child health services should be explored.

While it may seem a matter of common sense that women should be involved in the planning and implementation of projects and programmes that affect their livelihood, health and well-being, this is not the case, and women are often the last to benefit, if at all, from such interventions. Ways of incorporating the female perspective into these activities need to be investigated. The active involvement of women in the effort to combat endemic diseases can only serve to strengthen local health systems through the addition of an important reservoir of female resources.

\section{Acknowledgments}

The views expressed in this paper are those of the authors and do not necessarily reflect those of their host institutions.

\section{References}

Adagala, K. (1991) Households and historical change in plantations in Kenya. In: Women, Households and Change, pp. 158-179. Edited by E. Massini \& L. Stratigos. United Nations University, Tokyo.

Adamchak, D. J. \& Adebayo, A. (1987) Male fertility attitudes: a neglected dimension in Nigerian fertility research. Social Biol. 34, 57.

AGYEPONG, I. A. (1992) Ethnomedical perceptions and practice of malaria in an Adangme farming community. Social Sci. Med. 35, 131.

BabB, F. (1987) Between Field and Cooking Pot: The Economy of Market Women in Peru. Texas University Press, Texas.

BantJe, H. F. W. (1988) Female stress and birth seasonality in Tanzania. J. biosoc. Sci. $20,195$. Barclay, R. (1969) Filariasis in Sabah, East Malaysia. Ann. trop. Med. Parasitol. 63, 473.

Beljaev, A. E., Sharma, G. K., Brohult, J. A. \& Haque, M. A. (1986) Studies on the detection of malaria at Primary Health Centres. Part II. Age and sex composition of patients subjected to blood examination in passive case detection. Ind. J. Malar. $23,19$.

BIRD, C. E. (1991) Gender, time use, and health. J. Hlth social Behav. 32, 114.

Bonilla, E. (1992) La participacion de la mujer en el proceso de desarrollo en Ecuador. Informe de Progreso Economico y Social del Ecuador, IDB, Washington.

Bonilla, E., Kuratome, L. S., Rodriguez, P. \& Rodriguez, A. (1991) Salud y Desarrollo. Plaza \& Janes, Bogota.

BoSERUP, E. (1989) Population, the status of women and rural development. Popul. Dev. Rev. 15 (Suppl.), 45.

Brabin, B. J. (1991) The Risks and Severity of Malaria in Pregnant Women. Applied Field Research in Malaria Reports. No. 1. WHO/TDR, Geneva. 
Brabin, L. \& Brabin, B. J. (1992) Parasitic infections in women and their consequences. $A d v$. Parasitol. 31, 1.

Chandiwana, S. K. \& Christensen, N. O. (1988) Analysis of the dynamics of transmission of human schistosomiasis in the highveld region of Zimbabwe. Trop. Med. Parasitol. 39, 187.

Chatterjee, M. (1991) Indian Women. Their Health and Economic Productivity. World Bank, Washington, DC.

Cleland, J. \& van Ginneken, J. K. (1988) Maternal education and child survival in developing countries: the search for pathways of influence. Social Sci. Med. 12, 1357.

Clifford, W. B., LAKE, J. L. \& BRannon, Y. S. (1987) Spousal agreement on the value of children and fertility behavior. Popul. Envir. 9, 148.

CosmINSKY, S. (1987) Women and health care on a Guatemalan plantation. Social Sci. Med. 25, 1163.

DAS GuPTA, M. (1990) Death clustering, mothers' education and determinants of child mortality in rural Punjab, India. Popul. Dev. Rev. 13, 77.

DoAN, R. M. \& Bisharat, L. (1990) Female autonomy and child nutritional status: the extended-family residential unit in Amman, Jordan. Social Sci. Med. 38, 783.

Dyson, T. \& MOORE, M. (1983) Kinship structure, female autonomy, and demographic behaviour in India. Popul. Dev. Rev. 9, 35.

Elshtaln, J. B. (1981) Public Man, Private Woman. Women in Social and Political Thought. Princeton University Press, Princeton.

Ettling, M. B., Krongthong, T., Krachaklin, S. \& Bualombai, P. (1989) Evaluation of malaria clinics in Maesot, Thailand: use of serology to assess coverage. Trans. R. Soc. trop. Med. Hyg. 83, 325.

Feuoo, M. C. \& Jelin, E. (1987) Women from low income sectors: economic recession and democratization of politics in Argentina. In: The Invisible Adjustment. Poor Women and the Economic Crisis, pp. 27-54. Alfabeta, Santiago de Chile.

Feldmeier, H. \& KraNTZ, I. (1992) A synoptic inventory of needs for research on women and tropical parasitic diseases with an application for schistosomiasis. In: Women and Tropical Diseases, pp. 100-133. Edited by P. Wijeyaratne, E. M. Rathgeber \& E. St-Onge. Manuscript Report 314e. International Development Research Centre, Ottawa.

Feldmeier, H., Krantz, I. \& Poggensee, G. (1993) Gender-related biases in diagnosis and morbidity assessment of schistosomiasis and their implications for control operations. Acta Tropica, (in press).

FERGuson, A. (1986) Women's health in a marginal area of Kenya. Social Sci. Med. 23, 17.

Finerman, R. (1989) Who benefits from health-care decisions? Family medicine in an Andean Indian community. In: What We Know about Health Transition: The Cultural, Social and Behavioural Determinants of Health. Health Transition Series No. 2(II): 657, Canberra.

FLoREZ, C. E. \& Bonilla, E. (1991) The impact of the demographic transition in the Colombian family. In: Women Households and Change, pp. 30-62. Edited by E. Massini \& L. Stratigos. United Nations University, Tokyo.

Foucault, M. (1978) Historia de la Sexualidad. Siglo XXI, Madrid.

Graham, W. J. \& Campbell, O. M. R. (1990) Measuring Maternal Health: Defining the Issues. Publication No. 1. Maternal and Child Epidemiology Unit, London.

Harrison, K. A., Fleming, A. F., Briggs, N. D. \& Rossiter, C. E. (1985) Growth during pregnancy in Nigerian teenage primigravidae. Br. J. Obstet. Gynec. Suppl. 5, 32.

HibBaRD, J. H. \& POPE, C. B. (1983) Gender roles, illness orientation and use of medical services. Social Sci. Med. 17, 129.

Hossain, M. M. \& Glass, R. I. (1988) Parental son preference in seeking medical care for children less than five years of age in a rural community in Bangladesh. Am. J. publ. Hlth, 78, 1349. 
Huston, P. (1990) Invisible agents for change. Wld Hlth, April-May, 29.

Joesoef, M. R., Baughman, A. L. \& Utumo, B. (1988) Husband's approval of contraceptive use in metropolitan Indonesia: program implications. Stud. Fam. Plann. 19, 162.

KABEER, N. (1991) Gender dimensions of rural poverty: analysis from Bangladesh. J. Peasant Stud. 19, 241.

Kandrack, M. A., Grant, K. R. \& Segall, A. (1991) Gender differences in health related behaviour: some unanswered questions. Social Sci. Med. 32, 579.

KasejE, D. C. O., Sempebwa, E. K. \& Spencer, H. C. (1987) Malaria chemoprophylaxis to pregnant women provided by community health workers in Saradidi, Kenya. I. Reasons for non-acceptance. Ann. Trop. Med. Parasit. 81 (Suppl. 1), 77.

Khan, M. E., TAmang, A. K. \& PAtel, B. C. (1990) Work pattern of women and its impact on health and nutrition-some observations from the urban poor. J. Fam. Welfare, 36, 3.

Lariosa, T. R., Abaya, E. C. \& Ventura, E. R. (1987) Appraisal of Malaria and the Control Programme: The Case of Cabagan, Isabela, Philippines. SER/TDR final project report. WHO, Geneva.

Leslie, J., LyCette, M. \& Buvinic, M. (1986) Weathering Economic Crisis: The Crucial Role of Women in Health. International Center for Research on Women, Washington, DC.

Leslie, J. \& Rao GuPTA, G. (1989) Utilization of Formal Services for Maternal Nutrition and Health Care in the Third World. International Center for Research on Women, Washington, DC.

Loewenson, R., SAnders, D. \& Davies, R. (1991) Challenges to equity in health and health care: a Zimbabwean case study. Social Sci. Med. 32, 1079.

Malterud, K. (1987) Illness and disease in female patients. I, II. Scand. J. prim. Hith Care, 5, 205.

Mbacke, C. \& van DE WALle, E. (1987) Socio-economic factors and access to health services as determinants of child mortality. IUSSP Seminar on Mortality and Society in Sub-Saharan Africa. IUSSP, Yaounde.

McCauley, A. P., LyNCh, M., Pounds, M. B. \& WeST, S. (1990) Changing water-use patterns in a water-poor area: lessons for a trachoma intervention project. Social Sci. Med. 31, 1233.

MCGregor, I. A. \& Wilson, R. J. M. (1988) Specific immunity: acquired in man. In: Malaria. Principles and Practices of Malariology, Vol. I, pp. 558-619. Edited by W. H. Wernsdorfer. Churchill Livingstone, Edinburgh.

Mechanic, D. (1976) Sex, illness, illness behavior, and the use of health services. Social Sci. Med. 12B, 207.

MiCHELSON, E. H. (1992) Adam's rib awry: Women and schistosomiasis. In: Women and Tropical Diseases, pp. $24-40$. Edited by P. Wijeyaratne, E. M. Rathgeber \& E. St-Onge. Manuscript Report 314e. International Development Research Centre, Ottawa.

Murthy, N. (1982) Reluctant patients-the women in India. Wld Hlth Forum, 3, 315.

Okonofua, F. E., Feyisetan B. J., Davies-Adetugbo, A. \& Sanusi, Y. O. (1992) Influence of socioeconomic factors on the treatment and prevention of malaria in pregnant and nonpregnant adolescent girls in Nigeria. J. trop. Med. Hyg. 95, 309.

PAolisso, M. \& LesLIE, J. (1993) Meeting the changing health needs of women in developing countries. Social Sci. Med. (in press).

PARKer, M. (1992) Does schistosomiasis infection impair the health of women? In: Women and Tropical Diseases, pp. 81-99. Edited by P. Wijeyaratne, E. M. Rathgeber \& E. St-Onge. Manuscript Report 314e. International Development Research Centre, Ottawa.

PARKer, R. L. (1986) Health care expenditures in a rural Indian community. Social Sci. Med. 22, 23.

PaYne, S. (1991) Women, Health and Poverty. Harvester Wheatsheaf, New York. 
Popkin, B. M. \& DoAN, R. M. (1990) Women's roles, time allocation and health. What We Know about Health Transition: the Cultural, Social and Behavioural Determinants of Health. Health Transition Series No. 2(II), 683, Canberra.

PRESCOTt, N. (1989) Economic analysis of schistosomiasis control projects. In: Demography and Vector-Borne Diseases, pp. 155-163. Edited by M. W. Service. CRC Press, Boca Raton, Florida.

RaIkes, A. (1989) Women's health in East Africa. Social Sci. Med. 28, 447.

RATHgEBER, E. \& Vlassoff, C. (1993) Gender and tropical diseases: a new research focus. Social Sci. Med. 37, 513.

Reuben, R. (1992) Women and malaria. In: Women and Tropical Diseases, pp. 41-53. Edited by P. Wijeyaratne, E. M. Rathgeber \& E. St-Onge. Manuscript Report 314e. International Development Research Centre, Ottawa.

Reuben, R. \& PANicker, K. N. (1979) A study of human behaviour influencing man-mosquito contact, and of biting activity on children in a south Indian village community. Ind. J. med. Res. 70, 723.

SILvA, K. T. (1988) Malaria Control through Community Action at the Grass-Roots: Experience of the Sarvodaya Malaria Control Research Project in Sri Lanka from 1980 to 1986. SER Project Reports No. 4. WHO, Geneva.

Traore, S., Coulibaly, S. \& Sidibe, M. C. (1993) Comportements et couts liés au paludisme chez les femmes de campements de pêcheurs dans la zone de Selingue au Mali. SER Project Reports No. 12. WHO, Geneva.

UNICEF (1987) The Invisible Adjustment. Poor Women and the Economic Crisis. Alfabeta, Santiago de Chile.

United Nations (1991) The World's Women 1970-1990. Trends and Statistics (Social Statistics and Indicators, Series K, No. 8). United Nations, New York.

VERBRUGGe, L. M. (1985) Gender and health: an update on hypotheses and evidence. $J$. Hlth social Behav. 26, 156.

WATTS, S. J., BRIEGER, W. R. \& YACOOB, M. (1989) Guinea worm: an in-depth study of what happens to mothers, families and communities. Social Sci. Med. 29, 1043.

World Health Organization Special Programme for Research and Training in Tropical DiseaSes (TDR) (1991) Tropical Diseases. Progress in Research 1989-1990. Tenth Programme Report. WHO, Geneva.

Wyon, J. B. \& GoRdon, J. E. (1971) The Khanna Study: Population Problems in the Rural Punjab. Harvard University Press, Cambridge, Massachusetts.

Yoder, R. A. (1989) Are people willing and able to pay for health services? Social Sci. Med. 29, 35. 